\title{
Urinary stress incontinence and overactive bladder symptoms in older women
}

Pauline Chiarelli

Senior Lecturer

School of Health Sciences

University of Newcastle

Callaghan NSW, Australia.

\begin{abstract}
Urinary Incontinence - the accidental leaking of urine - is a major problem in Australia and has a significant impact on quality of life, affecting the social, psychological, physical and financial aspects of life. The prevalence of urinary incontinence is significantly higher in women than in men. While urine loss itself is a devastating symptom, older women are also likely to suffer lower urinary tract symptoms associated with the overactive bladder syndrome such as urgency, frequency, mixed incontinence and nocturia which are reported more frequently in older women. These symptoms disrupt activities of daily living as well as seriously disturbing sleep and general health status. Conservative nurse interventions have been shown to be effective in the management of these symptoms. Simple assessment tools suitable for use by primary level clinicians and conservative management strategies are discussed within the paper. words)
\end{abstract}

Key words: lower urinary tract; urinary incontinence; aging; conservative management; bladder training; pelvic floor muscle exercise; nursing

\section{What is I ncontinence?}

Incontinence - the accidental leaking of urine - is a major problem in Australia and has a significant impact on quality of life, affecting the social, psychological(Wyman et al. 1990), physical and financial (Doran et al. 2001) aspects of life. However, it is worth highlighting the fact that incontinence should not be considered a normal part of getting older nor, for women, should it be considered a normal part of having had children. 


\section{How common is urinary incontinence in women?}

A substantial number of both international (Hannestad et al. 2000, McGrother et al. 2006) and Australian studies (Chiarelli et al. 1999, MacLennan 2000) have examined the prevalence of female urinary incontinence. These estimates cover all types of urinary incontinence from infrequent loss of urine to regular, total incontinence.

Age stratified prevalence of urinary incontinence in Australian women clearly shows that urinary incontinence is not a condition experienced in the main by elderly women (Chiarelli et al. 2005) (See Table 1). The severity of urinary incontinence symptoms increases with age. Between 15\% and $20 \%$ of Australian women report either 'leaking often', requiring the some kind of continence aid, or being 'substantially dissatisfied with their urinary symptoms' (Miller et al. 2003).

$<$ Table 1 about here>

Urinary incontinence has been shown to impact significantly on the lives of older women. Who report greater social isolation (Wyman et al. 1990) more depressive symptoms (Dugan et al. 2000) and are at higher risk of admission to residential care (Tromp et al. 2001; Thom et al. 1997) and falls (Tromp et al. 2001 1997) when compared to their continent counterparts.

While urine loss itself is a devastating symptom, older women are more likely to suffer other lower urinary tract symptoms associated with the overactive bladder (OAB) such as urgency and nocturia. Such symptoms disrupt activities of daily living as well as seriously disturbing sleep and general health status (Asplund 2005).

\section{Incontinence and Lower Urinary Tract Symptoms}

There are four main LUTS: storage symptoms such as increased daytime frequency, nocturia (waking at night more than once to void), urgency (a sudden compelling urge to void that is hard to defer) and urinary incontinence (any involuntary leakage of urine) (Abrams et al. 2003). Bladder storage problems such as continuous urinary incontinence and conditions such as acute or chronic retention of urine are beyond the scope of this paper.

Urinary incontinence can be further distinguished into the following sub-types. (Abrams et al. 2003)

\section{Stress urinary incontinence}

Stress urinary incontinence is the complaint of involuntary leakage on effort or exertion or on 
sneezing or coughing (Abrams et al. 2002 2003). This symptom is experienced when weakened external continence mechanisms allow urine to leak from the bladder whenever there are increases in pressures within the abdomen. Increases in abdominal pressure occur when people cough, laugh, sneeze, blow their nose or during physical activity. External continence mechanisms include the urethral sphincter and the pelvic floor muscles being working in concert to squeeze around the urethra, shutting off the flow of urine from the bladder. The urethral closure pressure is enhanced by well vascularised urethra.

The pelvic floor muscles not only increase pressure around the urethra, they also lift the bladder neck higher within the pelvic cavity, effectively lengthening the urethra. This increases the functional length of the urethra, and consequently results in greater urethral closure pressure. (Abrams et al. 2003)

Stress urinary incontinence occurs when there is an increase in abdominal pressure greater than the maximum urethral closure pressure. Commonly, stress urinary incontinence is a result of weak pelvic floor muscles following childbirth, menopause and the normal changes in muscle strength that occur in the urethral and pelvic floor muscle as part of the ageing process (Wagg 2004).

While the prevalence and severity of urinary incontinence overall increase with age (Hannestad et al. 2000), the prevalence of stress incontinence in women increases during reproductive years (Chiarelli et al. 1999). The impact of age related changes on the severity of stress urinary incontinence is highlighted by two distinct age related peaks at age 60 years and again at age 80 years (Donaldson et al. 2006).

Overactive Bladder Syndrome $(O A B)$ is defined as urgency, with or without urgency incontinence, usually associated with symptoms of frequency and nocturia. OAB syndrome is a symptomatic diagnosis, the key symptom of which is urgency. Older people are more likely to experience leaking as a symptom of OAB (Abrams 2003).

Both the prevalence (Hannestad et al. 2000; McGrother et al. 2006) and severity of OAB symptoms increase with age, with an accelerated increase around 60 years (Donaldson et al. 2006).

Urgency incontinence is not a benign condition. Sufferers of $O A B$ with its unpredictable urgency and or urge incontinence can have a significant lowering of their quality of life (J ackson 1997) and are more likely to experience considerable co morbidity including accidental falls, fractures and urinary tract infections (Brown et al. 2000a,b). The psychological impact of OAB in older women is significant (Wagner et al. 2002) 
Nocturia

Defined by the International Continence Society as the complaint of waking at night, one or more times, to void (Abrams et al. 2002, 2003). About $45 \%$ of women aged less than 44 years and $62 \%$ of women aged more than 60 years report nocturia (Hunskaar 2005). Approximately $11 \%$ of people aged 60-70 years report multiple ( $\geq \times 3$ ) nocturnal voiding episodes (Asplund 2005). Again, nocturia is not the benign condition many think it is. Apart from sleep disturbances, the consequences of nocturia include daytime sleepiness loss of energy, falls and fractures (Asplund 2005, Brown et al. 2000b).

\section{Mixed Incontinence}

Mixed incontinence, is a combination of symptoms of both stress urinary incontinence and $\mathrm{OAB}$ (Abrams et al. 2003). Australian women reporting having leaked urine in the past year, were most commonly found to report symptoms of mixed incontinence (Miller et al. 2003) International studies also show mixed incontinence symptoms as the most common, particularly among older women (Hannestad et al. 2000).

Women who experience symptoms of urgency report more significant impact on their quality of life than women who have symptoms of stress incontinence alone (van der Vaart et al. 2002).

\section{Factors Contributing to Lower Urinary Tract Urinary Conditions in Older Women}

Age related changes within the lower urinary tract are more common than not (Resnick et al. 1995). Aging is associated with changes in urethral and pelvic floor muscle function, reductions in detrusor contractile function, detrusor compliance, and urinary flow rates. Age brings increases in post void urine residuals (Wagg 2004), and decreases in sensory bladder function and functional bladder capacity (Resnick et al. 1995). When coupled with age dependent decreases in mobility and manual dexterity, such age related changes deteriorations in bladder function increase the likelihood of embarrassing accidents.

A number of conditions of the nervous system common in the elderly have also been associated with incontinence including stroke (J orgensen et al. 2005), Parkinson's disease (Karram 1993). The relative risk of urinary incontinence in those with dementia has been shown to be 3 times higher in women and 3.6 times higher in men (Thom et al. 1997).

In older women, and especially frail elderly women the underlying causes of urinary incontinence are multifactorial, abut it is important to be aware that urinary incontinence is a significant factor associated with nursing home admission (Thom et al. 1997). 


\section{Assessment of lower urinary tract symptoms by primary level clinicians}

Urinary tract infection (UTI), urogenital atrophy, constipation and medications can contribute to LUTS in older women and should be excluded as possible causative factors before initial symptoms assessment can begin (Ouslander 2002).

Dipstick screening for UTI in older women has a high level of sensitivity when used in the primary care setting (Devillé et al. 2004) but other extrinsic factors that cause or contribute to LUTS in elderly women should be investigated by a medical practitioner (Cardozo 2007) and are outside the scope of this paper.

Since the risk of urinary incontinence is doubled in women reporting constipation(Chiarelli et al. 2000) and the management of constipation in elderly women has been shown to significantly reduce their experience of urinary incontinence and other LUTS (Charach et al. 2001), the experience of constipation should be included within the assessment of LUTS.

$O A B$ is a clinical syndrome not a urodynamic diagnosis (Moore 2006). While there are a number underlying causes of LUTS that might be reliably determined by urodynamics, careful evaluation using simple, valid and reliable questionnaires in conjunction with a bladder diary (sometimes called a frequency volume chart or voiding diary) can guide a clinician toward the most likely diagnosis, where conservative management is intended (Ishiko et al. 2000). Such questionnaires used together with a 3-day bladder diary (Dmochowski et al. 2005) can be used to differentiate the type of urinary incontinence or LUTS experienced by women, especially when the diary contains reported nocturia (Fink et al. 1999). A bladder diary records the times of micturitions and the voided volumes, incontinence episodes, pad usage and other information such as fluid intake, the degree of urgency and the degree of incontinence (Staskin et al. 2005). If a woman's symptoms are not explained by the diary, then further assessment is required (Cardozo 2007).

A simple, well validated scale can also be used to evaluate symptoms severity (Sandvik et al. 2006, Sandvik et al. 1993b). Both a bladder diary and the incontinence severity scale are two easy to use outcomes measures that might also be used to evaluate the efficacy of interventions, but there are other outcome measures available to primary level clinicians (Moore 2006).

\section{Management strategies for female lower urinary tract symptoms}


While conservative management strategies have an important role to play in the management of urinary incontinence and LUTS in older women, surgical interventions are commonly recommended for proven stress incontinence.

Surgical techniques used in the management of stress urinary incontinence use an open or closed abdominal or a vaginal approach. Recent surgical advances such as the tension free vaginal tape (TVT) have changed the surgical management of stress urinary incontinence. Such procedures are performed under local anaesthetic and may even be performed as out patient procedures (Moore 2006). While age in itself is no barrier to having surgery, evidence suggests that while surgery for stress urinary incontinence in older women improves symptoms, this improvement is likely to be less than the improvement gained in younger women(Sharp et al. 2006).

Surgery is uncommonly recommended as management for $O A B$ symptoms and is usually a last resort for $O A B$ symptoms resistant to all conservative interventions.

\section{Conservative management strategies for female lower urinary tract symptoms}

Conservative treatment options include lifestyle interventions, behavioural techniques and drug therapy and should be tailored to the needs of individuals. While medications are not commonly prescribed as first line management of stress urinary incontinence, they are often used in effective management of OAB (Herbison et al. 2003; Lemack 2001), and are even more effective if used together with behavioural interventions such as bladder training (Burgio et al. 1998). Behavioural interventions include such as interventions as pelvic floor muscle exercises and bladder training.

\section{Lifestyle interventions}

Recent evidence from a systematic review of the literature suggests that interventions aimed at modifying lifestyle risk factors associated with urinary incontinence might include advice related to reducing body mass index, alleviating or preventing constipation, and reducing the intake of carbonated beverages and caffeine (Chiarelli 2006).

\section{Pelvic floor muscle retraining}


Defined as repetitive, selective, voluntary contraction and relaxation of specific pelvic floor muscle (Abrams et al. 2003). A number of systematic reviews provide strong evidence to support the implementation of pelvic floor muscle exercise programs as a management tool for urinary incontinence (Berghmans et al. 2000; Hay-Smith et al. 2003) Treatment of stress incontinence is usually aimed at raising conscious awareness of the pelvic floor muscles as well as improving the pelvic floor muscle function and this can be achieved a number of ways. Age has proven to be no barrier to success (Nygaard et al. 1996) but motivation, having less severe levels of urinary incontinence, not having had previous surgery and adhering to exercise programs are clearly important patient variables in the success of such interventions (Lagro-J anssen 1991: 292). Pelvic floor muscle exercises have also been shown to be effective in the management of $O A B$ symptoms (Nygaard et al. 1996)

Pelvic floor exercises can be complemented by the use of various biofeedback techniques, but there is little evidence to show that the use of biofeedback improves outcomes of pelvic floor muscle training programs.

\section{How do pelvic floor muscle exercises improve LUTS?}

The pelvic floor muscles are a multilayered muscular plate that sits transversely across the pelvic outlet and has fixed attachments at either end. When the pelvic floor muscles contract effectively, there is increased tension within the muscle body accompanied by upward lifting movement as well as movement of the tailbone (Bo et al. 2001). The resulting muscle tension provides necessary resistance to any increases in abdominal pressure from above. Healthy PFM are multifunctional - they not only support all the pelvic organs but, by active contraction, they draw them upward, they making the urogenital hiatus smaller, and they play an important, active role in contributing to the urethral closing mechanisms that maintain continence of urine and the anorectal mechanisms that maintain continence of faeces (DeLancey 1990).

Treatment of stress incontinence aims to improve function by raising conscious awareness of the pelvic floor muscles. A tailored pelvic floor muscle exercise program improves muscle strength, and resting tone as well as improving the functional co-ordination of pelvic floor muscles and abdominal muscles. In a well conducted review of the effectiveness of pelvic floor muscle exercises in alleviating urinary incontinence, 29 out of 34 randomised controlled trails used strength training (HaySmith et al. 2003).

Studies have shown that PFM strength is not the only important component of adequate PFM function. The timing of a PFM contraction is of great importance i.e. knowing when to contract 
the PFM. Precontraction of the PFM significantly reduces bladder neck descent during coughing in women with stress urinary incontinence, (Miller et al. 1998) thus significantly reducing the amount of measured urine loss (Miller et al. 1997). This action is called 'the knack' and it seems reasonable to conclude that properly timing of a PFM contraction might be as important as the strength of the contraction.

Pelvic floor exercises also improve the resting tone of the muscles resulting in a better position of the bladder neck at rest as well during episodes of increased abdominal pressure (Balmforth et al. 2004). They have also proven effective in the management of symptoms of OAB (Sampselle et al. 2005).

Recent studies have shown that in continent women, there is a synergy between the contraction of the deep abdominal muscles and the PFM during a pelvic floor contraction.

Bo used EMG and studied the synergistic muscle activity of the pelvic floor muscles during contraction of other muscle groups and showed an association between PFM contraction and the abdominals but not with hip adductors or gluteal muscles (Bo \& Stein 1994). These results are supported by Sapsford who showed that the isometric abdominal exercise, using transversus abdominis and the obliques, activated the pubococcygeus muscle in postpartum women when performed with the pelvis tilted in the mid position (Sapsford et al. 2001). While both these studies included very small sample sizes $(n=6)$, they indicate a growing awareness of role of coactivation between the transversus abdominis and the muscles of the pelvic floor.

Pelvic floor muscle exercise programs

Nurse led pelvic floor muscle exercise programs have also been shown to be an effective management tool both for symptoms of $O A B$, and stress incontinence. A recent study by Sampselle et al. (2005) showed that following digital assessment of correct pelvic floor muscle contractions ability, continence promotion programs including pelvic floor muscle exercises were effective in older women (55-80 years) even when taught to groups.

There is no blanket prescription for pelvic floor muscle exercises and no evidence to support promotion of a particular exercise regime. Vaginal assessment of pelvic floor muscle function is considered essential since each woman needs a careful baseline assessment of her pelvic floor muscle function from which a tailored exercise program can be developed (Messelink et al. 2005b) and studies have shown that women are often unable to contract pelvic floor muscle after verbal instructions (Bump et al. 1991). It is recommended that digital palpation using a single finger be done in both supine and standing. The woman should be asked to 'lift and squeeze' (Messelink et al. 2005a). Such details as the length of time (in seconds) that a pelvic floor muscle contraction can be 
maintained and the number of pelvic floor muscle contractions able to be performed sequentially before tiring, form the basis of a tailored exercise program.

Bladder training

The most common treatment technique for symptoms of $O A B$ and urge incontinence is bladder retraining (Moore 2000). Bladder training aims to increase the bladder capacity and thus increase time between voids. Bladder training programs include pelvic floor exercises and deferment techniques such as squeezing up the pelvic floor muscles, mental distraction, deep relaxed breathing to learn to put off going to the toilet for longer and longer time periods. Bladder training focuses on improving conscious awareness of bladder control by educating the incontinent person in correct voiding habits, such as voiding when there is a need to void and not "just in case", and to progressively extend the interval between successive voids so that the bladder develops a greater capacity for storing urine, and the incontinent person develops better control over involuntary bladder contractions (Moore 2000). Pelvic floor exercise programs without the inclusion of bladder training have also been shown to be effective in the management of urge incontinence (Nygaard et al. 1996, Wyman et al. 1998, Moore 2000). Electrostimulation may also be used as part of a bladder training program with or without the use of anticholinergic medication to assist the overactive bladder (Moore 2000).

While pelvic floor exercises are effective in managing $O A B$, they are significantly more effective if combined with bladder training (Wyman 1998; Hay-Smith 2003), and equally effective when provided on an individual basis or as group training (J anssen et al. 2001). Home based, nurse delivered bladder training programs have also proven effective (McDowell et al. 1999).

\section{Mixed Incontinence}

Women experiencing mixed symptoms of stress urinary incontinence with $O A B$ urge symptoms are effectively managed using a combination of pelvic floor muscle exercises and bladder retraining techniques (Nygaard et al. 1996).

\section{Help seeking for urinary incontinence}

While it is known that early interventions aimed at reducing symptoms of stress and urge incontinence are most effective, women do seem to be reluctant to seek help for these problems (Byles 2003). Since women report being embarrassed about their lack of bladder control, healthcare professionals need to take a proactive approach in asking women under their care about their experience of LUTS. 


\section{Summary}

Urinary incontinence and other lower urinary tract symptoms are prevalent and costly in both psychosocial and financial terms; there are simple and effective conservative interventions available for those women with mild to moderate symptoms. The National Continence Management Strategy means that much is being done in Australia to help those suffering urinary incontinence as well as to prevent its onset. While continence nurse specialists play a major role in the management of urinary incontinence across all healthcare settings Australia, there is much that other nurses can do to prevent and manage incontinence by adopting a 'stop it' rather than 'mop' it approach to urinary incontinence.

\section{Further Resources}

The National Continence Foundation Helpline (1800 3300 66) for advice or contact your nearest nurse continence adviser or continence physiotherapist. 


\section{References}

Abrams P (2003) Describing bladder storage function: overactive bladder syndrome and detrusor overactivity. Urology 62: 28-37.

Abrams P, Cardozo L, Fall M, Griffiths D, Rosier P, Ulmsten U, Kerrebroeck Pv, Victor A and Wein A (2002) The Standardisation of Terminology of Lower Urinary Tract Function: Report from the standardisation sub-committee of the International Continence Society. Neurourology \& Urodynamics 21: 167-178.

Abrams P, Cardozo L, Fall M, Griffiths D, Rosier P, Ulmsten U, Kerrebroeck Pv, Victor A and Wein A (2003) The standardisation of terminology in lower urinary tract function: report from the standardisation sub-committee of the International Continence Society. Urology 61: 37-49.

Asplund R (2005) Nocturia in relation to sleep, health and medical treatment in theelderly. BJU International 96: 15-21.

Balmforth J, Bidmead J and Cardozo L (2004) Raising the tone: A prospective observational study evaluating the effect of PFMT on bladder neck mobility and associated improvement in stress urinary incontinence. Neurourology and Urodynamics 23: 553-554.

Berghmans L, Hhendricks, Debie R, Doorn Evwv, Bo K and Kerrebroek Pv (2000) Conservative management of urge urinary incontinence in women: a systematic review of randomised clinical trials. British Journal of Urology International 85: 254-263.

Bo K, Lilleas F, Talseth T and Hedland $\mathrm{H}$ (2001) Dynamic MRI of the pelvic floor muscles in an upright sitting position. Neurourology \& Urodynamics 20: 167-174.

Bo K and Stein R (1994) Needle EMG registration of striated urethral wall and pelvic floor muscle activity patterns during cough, valsalva, abdominal, hip adductor and gluteal muscle contractions in nulliparous healthy females. Neurourology and Urodynamics 13: 35-41.

Brown J, , Mcghan W and Chokroverty S (2000a) Comorbidities associated with overactive bladder. American Journal of Managed Care 6: S574-9.

Brown J, Vittinghoff E, J fwyman, Klstone, Mcnevitt, Ensrud K and Grady D (2000b) Urinary incontinence: does it increase risk for falls and fractures? Study of Osteoporotic Fractures Research Group. Journal of the American Geriatrics Society. 48: 721-5,.

Bump Rc, Hurst G, Fantl Ja and Wyman J (1991) Assessment of Kegel pelvic muscle exercise performance after brief verbal instruction. American Journal of Obstetrics and Gynaecology 165: 322-329.

Burgio K, Locher J, Goode P, Hardin M, Dowell Bm, Dombrowski M and Candib D (1998) Behavioural vs drug treatment for urge urinary incontinencein older women: a randomized controlled trial. Journal of the American Medical Association 280: 1995-2000.

Cardozo L (2007) The overactive bladder syndrome: treating patients on an individual basis. BJU International 99: 1-7.

Charach G, Greenstein A, Rabinovich P, Groskopf I and Weintraub M (2001) Alleviating constipation in the elderly improves lower urinary trract symptoms. Gerontology 47: 7276.

Chiarelli P (2006) Lifestyle interventions for pelvic floor dysfunction. IN BO, K., BERGMANS, B., KAMPEN, M. V. and MORKVED, S. (Eds.) Evidence Based Physiotherapy for the Pelvic Floor. Oxford, Elsevier Ltd.

Chiarelli P, Bower W, Attia J, Sibbritt D and Wilson A (2005) The prevalence of urinary and faecal incontinence in the community: a systematic review. Australasian Journal of Aging 24: 19-27.

Chiarelli P, Brown W and McElduf P (2000) Constipation in Australian women: prevalence and associated factors. International Urogynecology Journal and Pe/vic Floor Dysfunction 11: 71-78.

Chiarelli P, Brown W and McElduff P (1999) Leaking Urine - Prevalence and Associated Factors in Australian Women. Neurourology and Urodynamics 18: 567-577.

Delancey J (1990) Anatomy of the urethral sphincters and supports. InDrife J , Hilton P and Stanton S (Eds) Micturition. London, Springer-Verlag. 
Devillé W, Yzermans J, Duijn Nv, Bezemer P, Windt Dvd and Bouter L (2004) The urine dipstick test useful to rule out infections. A meta-analysis of the accuracy. BMC Urology 4:: 14 pages.

Dmochowski R, Sanders S, Appell R, Nitti V and Davila G (2005) Bladder-health diaries: an assessment of 3-day vs 7-day entries BJU International 96 1049-1054.

Donaldson M, Thompson J, Matthews R, Dallosso H, Mcgrother C (2006) The natural history of overactive bladder and stress urinary incontinence in older women in the community: a three year prospective cohort study. Neurourology \& Urodynamics 25: 706-716.

Doran C, Chiarelli P and Cockburn J (2001) Economic costs of urinary incontinence in Community dwelling Australian women. Medical Journal of Australia 174: 456-458.

Dugan E, Cohen S, Bland D, Preisser J, Davis C, Suggs P and Mcgann P (2000) The association of depressive symptoms and urinary incontinence among older adults. Journal of the American Geriatrics Society 48: 413-416.

Fink D, Perucchini D, Schaer $G$ and Uhaller (1999) The role of the frequency-volume chart in the differential diagnostic of female urinary incontinence. Acta Obstetricia et Gynecologica Scandinavica 78: 254-257.

Hannestad Y, Rortveit G, Sandvik H and Hunskaar S (2000) A community-based epidemiological survey of female urinary incontinence: The Norwegian EPINCONT study. Journal of Clinical Epidemiology 53: 1150-1157.

Hay-Smith E, Bo K, Berghmans L, Hendricks H, Bie Rd and Doorn Evwv (2003) Pelvic floor muscle training for urinary incontinence in women (Cochrane Review), Chichester England., John Wiley and Sons.

Herbison P, Hay-Smith J, and Moore K (2003) Effectivemess of anticholinergic drugs compared with placebo in the treatment of overactive bladder: Systematic review. British Medical Journal 326.

Hunskaar S (2005) Epidemiology of Nocturia. BJU International 96: 4-7.

Ishiko O, Sumi T, Hirai K and Ogita S (2000) Classification of female urinary incontinence by the scored incontinence questionnaire. International J ournal of Gynaecology \& Obstetrics. 69 255-260.

Jackson S (1997) The patient with overactive bladder symptoms and quality of life issues. Urology 50: $18-22$.

Janssen C, Lagro-Janssen A and Felling A (2001) The effects of physiotherapy for female urinary incontinence: individual compared with group treatment. British Journal of Urology International 87: 201-206.

J orgensen L, Engstad T and Jacobsen B (2005) Self-reported urinary incontinence in noninstitutionalized long-term stroke survivors: a population based study. Archives of Physical Medicine and Rehabilitation 86: 416-420.

Karram Mm (1993) Detrusor instability and hyperreflexia. IN WALTERS, M. and KARRAM, M. (Eds.) Clinical Urogynecology. St Louis, CVMosby.

Lemack G (2001) Overactive bladder: Optimizing quality of care. American Journal of Managed Care 7: S46-S61.

Maclennan A (2000) The prevalence of pelvic floor disorders and their relationship to gender, age, parity and mode of delivery. British Journal of Obstetrics and Gynaecology 107: 14601470.

Mcdowell B, Engberger S, Serieka S, Donovan N, Jubeck M, Weber E and Engberg R (1999) Effectiveness of behavioral therapy to treat incontinence in homebound older adults. Journal of the American Geriatrics Society 47: 309-318.

McGrother C, Donaldson M, Hayward T, Matthews R, Dallosso H, Hyde C (2006) Urinary storage symptoms and comorbidities: a prospective population cohort study in middle-aged and older women. Age and Ageing 35: 16-24.

Messelink B, Benson T, Berghmans B, Bo K, Corcos J, Fowler C, Laycock J, Lim P, Vanlunsen R, Nijeholt G, Pemberton J, Wang A, Watier A and Kerrebroeck Pv (2005a) Standardisation of Terminology of Pelvic Floor Muscle Function and Dysfunction: Report from the Pelvic Floor Clinical Assessment Group of the International Continence Society. Neurourology and Neurodynamics 23: 374-380.

Messelink B, Benson T, Berghmans B, K Bø J, Fowler C, Laycock J, Lim P, Lunsen R, G Lycklama Á Nijeholt, Pemberton J, Wang A, Watier A and Kerrebroeck P (2005b) Standardization of 
terminology of pelvic floor muscle function and dysfunction: Report from the pelvic floor clinical assessment group of the International Continence. Neurourology and Urodynamics 24: 374 - 380.

Miller J, Ashton-Miller J and Delancey J (1998) A pelvic muscle precontraction can reduce coughrelated urine loss in selected women with mild SUI. Journal of the American Gerontological Association 46: 870-874.

Miller M, Ashton-Miller K, Carchidi L and Delancey J (1997) Does a three month pelvic muscle exercise intervention improve the effectiveness of the knack in reducing cough induced urine loss on a standing stress test? International Urogynecology Journal and Pe/vic Floor Dysfunction 8: 253.

Miller Y, Brown W, Russel A and Chiarelli P (2003) Urinary incontinence across the lifespan. Neurourology and Urodynamics 22: 550-557.

Moore K (2000) Conservative management for urinary incontinence. In Cardozo L (Ed.) Bailliere's Clinical Obstetrics and Gynaecology : Urinary Incontinence. London, Harcourt.

Moore Kh (2006) Urogynecology: evidence based clinical practice London, Springer-Verlag.

Nygaard I, Kreder K, Lepic M, Fountain K and Rhomberg A (1996) Efficacy of pelvic floor muscle exercises in women with stress, urge and mixed incontinence. American Journal of Obstetrics and Gynaecology 174: 120-125.

Ouslander J (2002) Geriatric considerations in the diagnosis and management ofoveractive bladder. Urology 60: 50-55.

Resnick N, Elbadawi A and Yalla S (1995) Age and the lower urinary tract: what is normal? Neurourology \& Urodynamics 14: 577-579.

Sampselle C, Messer K, Seng J, Raghunathan T, Hines S and Diokno A (2005) Group behaviour modification program increased knowledge and practice of pelvic floor muscle training. International Urogynecology Journal and Pelvic Floor Dysfunction 16: 441-446.

Sandvik H, Espuna M and Hunskaar S (2006) Validation of the incontinence severity index: comparison with pad weighing tests. International Urogynecology Journal and Pelvic Floor Dysfunction 17: 520-524.

Sandvik H, Hunskaar S, Seim A, Hermstad R, Vanvik A and Bratt H (1993b) Validation of a severity index in female urinary incontinence and its implementation in an epidemiological survey. Journal of Epidemiology and Community Health 47: 497-499.

Sapsford R, Hodges P, Richardson C, Cooper D, Markwell S and J ull G (2001) Co-activation of the abdominal and pelvic floor muscles during voluntary exercises. Neurourology \& Urodynamics. 20: 31-42.

Sharp V, C Bradley C and Kreder K (2006) Incontinence surgery in the older woman. Current Opinion in Urology 16: 224-8.

Staskin D, Emmanuel P, Goode P, Mills I, Schull B, Yoshiba M and Zubieta R (2005) Chapter 9. Initial assessment of incontinence. IN Abrams, P., Cardozo, L., Khoury, S. and Wein, A. (Eds.) Proceedings of the third international consultation on incontinence. Health Publication Ltd.

Thom D, Haan M and Eeden Svd (1997) Medically recognized urinary incontinence and risks of hospitalisation, nursing home admission and mortality. Age and Ageing 26: 367-374.

Tromp A, Pluijm S, Smit J, Deeg D, Bouter L and Lips P (2001) Fall-risk screening test: a prospective study on predictors for falls in community-dwelling elderly. Journal of Clinical Epidemiology 54: 837-844.

Vandervaart C, Leeuw Jd, Roovers J and Heintz A (2002) The effect of urinary incontinence and overactive bladder symptoms on quality of life in young women. BJU Int 90: 544-549.

Wagg A (2004) Urinary incontinence--older people: where are we now? BJOG 111: 15-9.

Wagner Th, Hu T-W, Bentkover J, Leblanc K, Stewart W, Corey R, Zhou Z, and Hunt T (2002) Health-related consequences of overactive bladder. American Journal of Managed Care 8: S598-607.

Wyman J, Fantl J, McClish D and Bump R (1998) Comparative efficacy of behavioral interventions in the management of female urinary incontinence. Continence Program for Women Research Group. American Journal of Obstetrics \& Gynecology. 179.: 999-1007.

Wyman J, Harkins S and Fantl J (1990) Psychosocial impact of urinary incontinence in the community dwelling population. Journal of the American Geriatrics Society 38: 282-288. 
Table1 : Estimated prevalence of urinary incontinence in different age groups of Australian women

\begin{tabular}{lcrl} 
& $\begin{array}{l}\text { Number of } \\
\text { Australian } \\
\text { women in this } \\
\text { age group }\end{array}$ & \multicolumn{2}{l}{$\begin{array}{l}\text { Proportion of } \\
\text { women } \\
\text { incontinent } \\
\text { this age } \\
\text { group in }\end{array}$} \\
$\begin{array}{l}\text { Age } \\
\text { group } \\
<40\end{array}$ & $5,414,884$ & 0.165 & $\begin{array}{l}\text { Number of } \\
\text { incontinent } \\
\text { Australian } \\
\text { women in this } \\
\text { age group } \\
893,721\end{array}$ \\
$40-49$ & $1,373,537$ & 0.209 & 286,495 \\
$50-59$ & $1,042,819$ & 0.257 & 268,427 \\
$60-69$ & 725,572 & 0.203 & 147,125 \\
$70-79$ & 611,470 & 0.235 & 143,443 \\
$80+$ & 343,574 & 0.284 & 97,695 \\
Total & $\mathbf{9 , 5 1 1 , 8 5 6}$ & & $\mathbf{1 , 8 3 6 , 9 0 6}$
\end{tabular}

